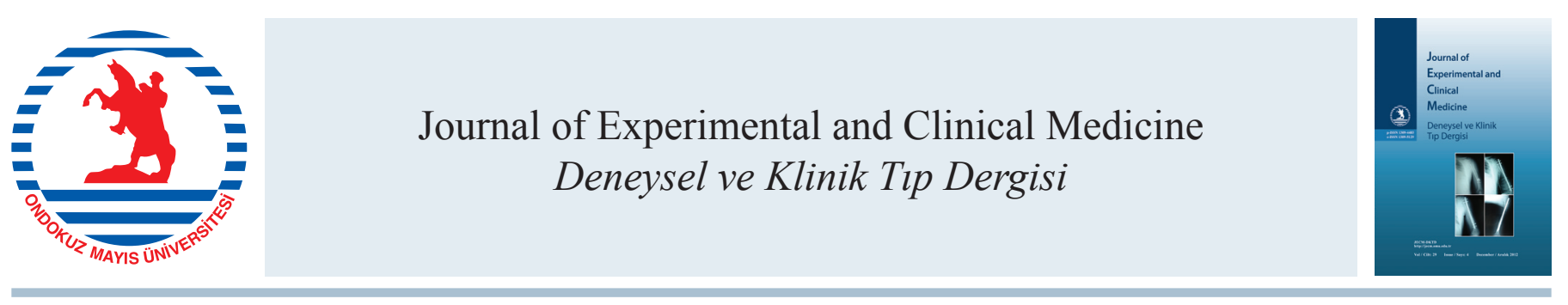

Klinik Araştırma / Clinical Research

doi: $10.5835 /$ jecm.omu.29.04.005

\title{
Hematolojik hastalıklarda splenektomi; tek merkez deneyimi
}

\author{
Splenectomy in haematological diseases; single center experience \\ Manolya Görkemª, M. Hilmi Atay ${ }^{\mathrm{b}}$, Engin Kelkitli*b, Piltan Büyükkayab ${ }^{\mathrm{b}}$, Düzgün Özatlı ${ }^{\mathrm{b}}$, Nil Gülerb, Mehmet Turgut ${ }^{\mathrm{b}}$ \\ ${ }^{a}$ Ondokuz Mayıs Üniversitesi, Tıp Fakültesi, İ̧ Hastalıkları Anabilim Dalı, Samsun, Türkiye \\ ${ }^{b}$ Ondokuz Mayıs Üniversitesi, Tıp Fakültesi, İç Hastalıkları Anabilim Dalı, Hematoloji Bilim Dalı, Samsun, Türkiye
}

\begin{tabular}{|c|c|}
\hline MAKALE I & GÍLERİ \\
\hline Makale geçı & \\
\hline Geliş tarihi & : $02 / 01 / 2012$ \\
\hline Kabul tarihi & : 22 / $03 / 2012$ \\
\hline
\end{tabular}

\section{* Yazışma Adresi:}

Engin Kelkitli

Ondokuz Mayıs Üniversitesi

Tip Fakültesi,

Hematoloji Anabilim Dalı,

Samsun

e-posta: ekelkitli@gmail.com

\author{
Anahtar Kelimeler: \\ Hematolojik hastalıklar \\ Splenektomi \\ Aşı \\ Komplikasyon
}

\section{Keywords:}

Haematological diseases

Splenectomy

Vaccine

Complication

\section{ÖZET}

Splenektomi, medikal tedaviye dirençli ve agresif seyreden hematolojik hastalıklarda önemli bir tedavi seçeneğidir. Diğer yandan bir kısım hematolojik hastalıklarda ise tanı amacıyla splenektomi yapılır. Bu çalışmada, kliniğimizde hematolojik nedenlerle tanı veya tedavi amaçlı splenektomi yapılan hastaları ve sonuçlarını sunmayı amaçladık. $\mathrm{Bu}$ çalışmada Eylül 2005 ile Mayıs 2011 tarihleri arasında Ondokuz Mayıs Üniversitesi Tıp Fakültesinde splenektomi yapılan 184 hasta retrospektif olarak incelendi. Çalışmaya Hematoloji polikliniğine başvuru yapan ve hematolojik hastalığı nedeniyle splenektomi yapılan 54 hasta dahil edildi. Hastaların 34'ü (\%63) kadın, 20'si (\%37) erkek idi.

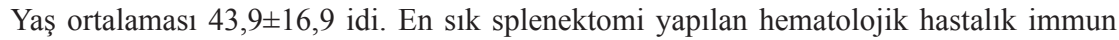
trombositopenik purpura (ITP) $(\% 70,4)$ idi. 53 hastada tedavi ve bir hastada tanisal amaçlı splenektomi yapılmıştı. Tanısal amaçlı splenektomi yapılan hastada patoloji sonucu Hodgkin lenfoma idi. Hastaların en sık ön plana çıkan semptomları cilt lezyonları idi (peteşi, purpura, ekimoz). Hastaların dalak boyutu değerlendirildiğinde $38(\% 70,4)$ hastanın dalak boyutları normaldi. ITP tanılı hastaların 35'inde $(\% 92,1)$ dalak boyutu normal sinırlarda bulundu. Hastaların 16'sinda $(\% 29,6)$ hepatomegali saptandı. Ameliyat sırasında \%13 hastada aksesuar dalak tespit edildi. En sik bildirilen dalak patoloji sonucu hipersplenizm idi. 46 hastaya ameliyat öncesi, 16 hastaya ise ameliyat sonrası pnömokok ve hemofilus influenza aşıları yapılmıştı. Meningokok aşısı temin edilemediğinden yapılamadığı tespit edildi. Cerrahi komplikasyonlara bağlı ölüm izlenmedi. Sonuç olarak splenektomi hematolojik hastalarda tanı ve tedavide güncelliğini korumaktadır. Yeni tanı ve tedavi yöntemlerinin gelişmesiyle bir kısım hematolojik hastalıklarda splenektomi sıklığının azalacağı kanaatindeyiz. Bununla birlikte konu ile ilgili yapılacak olan çok merkezli ve geniş vaka serili yayınlara ihtiyaç vardır.

J. Exp. Clin. Med., 2012; 29:276-279

\section{ABSTRACT}

Splenectomy is an important treatment option in some haematologic diseases which are aggressive and refractory to medical treatment. Splenectomy is also used for diagnosis for some of the hematologic diseases. In this study, we aimed to present the patients and the results of the diagnostic and therapeutic splenectomy due to haematologic diseases. In this study, between September 2005 and May 2011, in Ondokuz May1s University Faculty of Medicine, 184 patients with splenectomy were retrospectively reviewed. Fifty four patients were included who applied to Haematology Clinic and had splenectomy due to haematological diseases. 34 (63\%) of patients were female and 37\% (20) were male. The mean age was $43.93 \pm 16.9$. The most common haematologic disease for which splenectomy was immune thrombocytopenic purpura (ITP) (70.4\%). Splenectomy was applied for therapeutic purpose in 53 patients and for diagnostic purpose in 1 patient. The pathology result was Hodgkin lymphoma in the patient who receieved diagnostic splenoctomy. The most common presenting symptoms of the patients were skin lesions (petechiae, purpura, ecchymosis). Spleen size had within the normal range in $38(70.4 \%)$ patients. Normal spleen size was observed in 35 ITP patients (92.1\%) . 16 patients $(29.6 \%)$ had hepatomegaly. Accessory spleen was found in $13 \%$ of patients during surgery. The most frequently reported result of splenic pathology was found to be hypersplenism. 46 patients before surgery, 16 patients after the surgery had pneumococcal and haemophilus influenza vaccines. Meningococcal vaccine could not be done because it could not be obtained. Death due to surgical complications was not observed. As a result, splenectomy, 
is still used for diagnosis and treatment in hematological diseases, at diagnosis and treatment remains up to date. The development of new diagnostic and treatment methods would decrease the frequency of splenectomy in some hematologic diseases. However, large multi-center case-serial publications will be needed.

J. Exp. Clin. Med., 2012; 29: 276-279

\section{Giriş}

Dalak, hem humoral bağışıklıkta hem de hücresel bağışıklıkta rol alır. Kan dolaşımındaki bakterilere karşı spesifik antikor yapılması, T ve B lenfositlerin olgunlaştırılması, antikorla işaretli hücrelerin fagositozu, tufsin ve properdin yap1$\mathrm{m}$ gibi immünolojik fonksiyonları vardır. Dalaktaki makrofaj ve histiyositler, antikor ya da opsonik proteinle işaretli bakterileri fagosite ederek ortadan kaldırırlar. Bu nedenle dalak, organizmayı enfeksiyonlara karşı korumada önemli bir fonksiyon üstlenmiştir ( Porembka ve ark., 2009). Hematolojik hastalıklarda splenektomiyi, Sutherlend ve Burghard 1910 y1lında ilk olarak herediter sferositoz tedavisinde ve Kaznelson 1916 yllinda idiopatik trombositopenik purpura tedavisinde tanımladilar (Coad ve ark., 1993; Balague ve ark., 2004). Günümüzde dalak fizyolojisi ve fonksiyonlarının daha iyi anlaşılması; bir kısım hematolojik hastalıkların splenektomi ile tedavi edilebileceğini, diğer bir kısmında ise splenektominin palyatif bir etkisi olduğunu ortaya koymuştur. Bu çalışmada, kliniğimizde hematolojik hastalık nedeniyle tanı veya tedavi amaçlı splenektomi yapılan hastaları ve sonuçlarını sunmayı amaçladik.

\section{Araştırma Yöntemi}

Bu çalışmada Eylül 2005 ile Mayıs 2011 tarihleri arasında Ondokuz Mayıs Üniversitesi Tıp Fakültesi'nde splenektomi yapılan 184 hasta retrospektif olarak incelendi. Çalışmaya Ondokuz Mayıs Üniversitesi Hastanesi Hematoloji Polikliniği'ne başvuran ve hematolojik hastalığ splenektomi yapılan 184 hastanın 54'ü dahil edildi. Veriler hasta dosyaları taranarak elde edildi. Travma, kist, tümör nedenleriyle splenektomi yapılan hastalar çalışma dişı bırakıldı. Hastalar yaş, cinsiyet, hematolojik hastalıkları, dalak boyutu, hepatomegali varlığ 1 , hastaneye başvuru semptomu, aksesuar dalak varlığı, kemik iliği biyopsi sonucu, dalak patoloji sonucu, splenektomiye bağlı morbidite ve mortalite açısından değerlendirildi. Dalak boyutu $\geq 13 \mathrm{~cm}$ olanlar splenomegali, karaciğer boyutu $\geq 16 \mathrm{~cm}$ olanlar hepatomegali olarak kabul edildi. Splenektomi öncesi ve sonrası aşı öyküsü, hastalar telefonla aranarak ve hasta dosyaları taranarak elde edildi. Veriler retrospektif bir şekilde kayıt edildi.

Araştırmadan elde edilen veriler kodlandıktan sonra SPSS 15,0 paket programında bilgisayara aktarıldı ve analiz edildi. Verilerin tanımlayıcı özellikleri ortalama \pm standart sapma, sayı ve yüzde olarak ifade edilmiştir. İstatistiksel analizlerde tüm ölçümsel değişkenler için normalite testleri yapılmıştır. Gruplar arası karşılaştırmalarda Kruskal-Wallis testi ve Mann-Whitney U-testi kullanıldı. Sayımla elde edilen verilerin karşılaştırmasında ise Ki kare testi kullanıldı. İstatistiksel anlamlılık düzeyi $\mathrm{p}<0,05$ olarak kabul edilmiştir.

\section{Sonuçlar}

Çalışmamızda hastaların 20’si (\%37) erkek, 34’ü (\%63) kadındı. Çalışmaya alınan hastaların yaş aralığı 19-89 arasın-

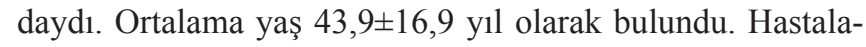
rın tedavi amaçlı splenektomi yapılanların otuzsekizi immün trombositopenik purpura (ITP), beşi otoimmün hemolitik anemi (OHA), dördü herediter sferositoz (HS), dördü Hairy cell lösemi (HCL), biri kronik lenfositer lösemi (KLL) ve bir hasta Gaucher hastası idi. Tanısal amaçlı splenektomi yap1lan bir hasta Hodgkin lenfoma (HL) tespit edildi. Hastaların dalak boyutu, \%70,4'ünde (38) normal aralıkta tespit edildi. Hastalıklara göre dalak boyutu değerlendirildiğinde ise immun trombositopenik purpuralı hastaların \%92,1'inde (35) normal sinırlarda bulundu.

Tüm hastaların karaciğer boyutu değerlendirildiğinde hastaların \%29,6'sında (16) hepatomegali saptanmıştır. Hepatomegali saptanan 16 hastanın 6's1 ITT'li, 3'ü HS'li, 2'si OHA'l, 2'si HCL'li, biri KLL'li, biri HL'li, biri Gaucher hastasıydı. Hastaların \%13'ünde ameliyat sırasında aksesuar dalak tespit edildi. İmmun trombositopenik purpuralı hastaların \%13,2'sinde ( $\mathrm{n}=5)$ aksesuar dalak saptanmıştır.

Çalışmamızda hastaların 28'ine kemik iliği aspirasyon ve biyopsisi yapılmıştı. İTP hastalarının 16'sında kemik iliğinde megakaryosit sayısında artış gösteren kemik iliği, ikisinde ise normosellüler kemik iliği rapor edildi. İki OHA'lı hastada kemik iliğinde yetersiz eritropoetik aktivite görüldü. HS'li bir hastada megakaryositlerde displazi ve retikülin lif artışı mevcuttu. HCL'li 4 hastanın kemik iliğinde lösemik infiltrasyon tespit edildi. KLL hastası kemik iliğinde lenfositik hücre infiltrasyon saptandı. Gaucher hastası kemik iliğinde Gaucher hücreleri izlendi. Hodgkin hastalığı tanısı konulan hastanın kemik iliği hiposelüler olarak rapor edildi.

Çalışmamızda hastalarda splenektomi öncesi ve sonrası aşılanma öyküleri sorgulandı. 54 hastanın 46'sından net bilgi alınabildi. Toplam 46 hastaya splenektomi öncesi, 16 hastaya splenektomi sonrası, 13 hastaya ise hem splenektomi öncesi hem splenektomi sonrası pnömokok ve influenza aşıları uygulandığı tespit edildi. Splenektomi sonrası dönemde aşı uygulanan 16 hastanın düzensiz aralıklarla aşılandığı öğrenildi. Meningokok aşısı temin edilemediğinden yapılamadığı tesbit edildi.

Çalışmamızda tüm hastalar splenektomiye bağlı mortalite ve morbidite açısından değerlendirildi. Hiçbir hastada ameliyat sırasında ölüm ve komplikasyon görülmedi. 6 hastada splenektomi sonrası komplikasyon gelişti. Bu hastaların 5'i ITP tanılı hasta, biri ise KLL tanılı hasta idi. Komplikasyon gelişen hastaların ikisinde splenik hematom, bir hastada

Tablo 1. Splenektomi esnasında ve sonrasında ölüm ve komplikasyon gelişen hasta sayısı

\begin{tabular}{lcc} 
Splenektomi & $\begin{array}{c}\text { Ölüm } \\
\text { (n=hasta sayısı) }\end{array}$ & $\begin{array}{c}\text { Komplikasyon } \\
\text { (n=hasta sayısı) }\end{array}$ \\
\hline Ameliyat esnasında & 0 & 0 \\
Ameliyat sonrası & 1 & 2 (Splenik Hematom) \\
& & 1 (Pnömoni) \\
& 1 (Yara Enfeksiyonu) \\
& 1 (Pulmoner Emboli) \\
\hline
\end{tabular}


pnömoni, bir hastada yara yeri enfeksiyonu tespit edildi. Bir hasta splenektomiden bir ay sonra pulmoner emboli gelişti. Bir hasta ise ameliyattan bir ay sonra sepsis nedeniyle kaybedildi. Tablo 1'de splenektomiye bağl1 gelişen ölüm ve komplikasyonlar özetlemiştir.

\section{Tartışma}

Dalak, insan vücudunda çok önemli fizyolojik fonksiyonlara sahip bir organdır. Dolaşıma katılan mikroorganizmaların filtre edilmesi, spesifik IgM antikorların sentezlenmesi, anormal kan hücrelerinin dolaşımdan uzaklaştırılması örnek olarak gösterilebilir (Eichner, 1979). Bazı patolojik durumlarda, dalak fonksiyonlarını yerine getiremez ve hatta hematopoetik elemanların destrüksiyonuna yol açar. Bu nedenle hematolojik hastalıkların tanısında ve tedavisinde terapötik amaçlı olarak splenektomi yapılmaktadır. Girgin ve arkadaşlarının (2008) yaptığ 1 çalışmada hematolojik nedenle splenektomi yapılan 115 hastanın \%56 'sında neden ITP idi. Namir ve arkadaşlarının yaptığı bir çalışmada ise 103 hastanın \%65'ine ITP ve \%11'ine HS nedeniyle splenektomi yapılmıştı (Katkhouda ve ark., 1998).Litaretürle uyumlu olarak hastalarımızın \%70,4'ünde İTP, \%9,4'ünde OHA nedeniyle splenektomi uygulanmıştı.

Hastaları dalak boyutu bakımından değerlendirdiğimizde 38 hastanın dalak boyutunun normal $(\% 70,4)$ aralıkta olduğu tespit edilmiştir. Hastalıklara göre dalak boyutu değerlendirilğinde ITP hastalarının \%92,1 (35) 'inde dalak boyutu normal sinırlarda bulundu. Katkhouda ve ark. (1998) hematoloji hastalığı nedeniyle 103 splenektomi yapılan hastayı kapsayan araştırmasında ITP hastaların \%92'sinin dalak boyutlarının normal aralıkta olduğu tespit edilmişti. KLL, HCL, HL gibi malign hemotoloji hastalıkları nedeniyle splenektomi yapılan hastalaramızda ise ortalama dalak boyutu $21 \mathrm{~cm}$ olarak bulundu. Schlachta ve ark. (1999) çalışmasında hastaların ortalama dalak boyutu $17 \mathrm{~cm}$ olarak tespit edilmişti. Bu nedenle İTP hastalarında dalak boyutunun öncelikle normal olacağ1 ve dalak boyutu normalden büyük olan hastalarda daha çok ITP dışındaki hematolojik hastalıklar akılda tutulmalıdır.

Hematolojik hastalıklarda splenektomi yapılanlarda aksesuar dalağın geride bırakılması durumunda hematolojik cevabın zayıf olduğu açıktır (Musser ve ark., 1984). Musser ve ark. (1984) 306 splenektomi olan hastayı kapsayan çalışmasında aksesuar dalak sıklığı \%19 olarak saptanmıştı. Splenektomi olan hastalarımızın \%13'ünde aksesuar dalak tespit edilmişti. Bu nedenle aksesuvar dalak için preoperatif tanı yöntemleri kullanılmalı ve ameliyat sırasında dikkatli bir araştırma yapılması gereklidir.

Çalışmamızda 46 hastaya $(\% 87,1)$ splenektomi öncesi, 8 hastaya $(\% 12,9)$ splenektomi sonras1, 13 hastaya ise $(\% 24)$ splenektomi öncesi ve sonrası aşı uygulandığı tespit edildi. Özkören ve arkadaşlarının yaptığı çalışmada splenektomi yapılan 36 hastanın 15 inde (\%41) splenektomi öncesi, 12 'sinde $(\% 33,3)$ splenektomi sonrası aşı yapıldığı tespit edilmiştir(Özkören ve ark., 2007). Bizim çalışmamızda olduğu gibi bu çalışmada da hastaların çoğu aşılanıp aşılanmadığını bilmemektedir. Splenektomi sonrası enfeksiyon gelişme riski etiyoloji açısından değerlendirildiğinde en yüksek oran hematolojik hastalıklardır (Schwartz ve ark., 1982; Ejstrud ve ark., 2000). Kural olarak elektif koşullarda splenektomi yapılacak olgulara splenektomiden en az iki hafta önce pnömokok ve $H$. influenza tip b konjuge aşıları yapılmalıdır ( Davies ve ark., 2002). Splenektomi sonrasında yapılan bağışıklamanın etkinlik ve koruyuculuğunun az olduğu bildirilmekle birlikte acil splenektomi sonrasında da iki hafta içinde aşı uygulanması önerilmektedir. Yine önceden yapılmadıysa meningokok aşısı ve her yıl influenza aşısı uygulanmalıdır (Lutwick, 2005). Splenektomi sonrası kapsüllü bakterilere karşı duyarlılığın artması nedeni ile ortaya çıkabilecek enfeksiyonlar ve buna bağlı hastanede yatış sürelerinin artması ve kullanılan ilaçların ciddi ekonomik külfeti düşünüldüğünde splenektomi öncesi aşılanmanın önemi daha da artmaktadır. Yapılan bu iki çalışmadan anlaşılacağı üzere ülkemizde splenektomi öncesi yapılacak olan aşılama çok önemli gibi durmaktadır. Bu nedenle splenektomi yapılması planlanan hastalara mutlaka aşı kartlarının hazırlanıp verilmesi ve bu kartların kontrollerde dikkatli bir şekilde değerlendirilmesinin faydalı bir yöntem olacağ1 düşüncesindeyiz.

Wang ve arkadaşlarının yaptığı çalılışmada splenektomi yapılmış 149 ITP hastası ameliyata bağlı ölüm oranı $\% 0,7$ olarak saptanmıştır. Ayrıca bu çalışmada yara infeksiyonu 2 hastada $(\% 1,3)$, pnömoni $4(\% 4)$, diyafragma altında siv1 birikimi 31 hastada (\% 20,8), kombine infeksiyon 1 hastada $(\% 0,7)$ tespit edilmiştir (Wang ve ark, 2005). Çalışmamızda splenektomi yapılan İTP hastalarının hiçbirinde ameliyata bağlı ölüm görülmedi. Ameliyat sonrası komplikasyon olarak bir hastada pnömoni, 2 hastada splenik hematom, bir hastada yara yeri infeksiyonu ve bir hastada pulmoner emboli gelişti. Bir hasta ameliyattan bir ay sonra sepsis nedeniyle kaybedildi. Hastanın ameliyat öncesi pnömokok ve $H$. Influenza aşıları yapılmıştı. Cerrahiye bağlı komlikasyon oranlarının az görülmesi hastanemizdeki cerrahi ekiplerin başarısı ve cerrahi yoğun bakımın gelişmesiyle yakından ilişkilidir. Sonuç olarak; splenektomi hematolojik hastalarda tanı ve tedavide güncelliğini koruduğu anlaşılmaktadır. Yeni tedavi yöntemlerinin gelişmesiyle gelecek yıllarda bir kısım hastalıklarda splenektomi sıklığının azalacağı kanaatindeyiz. Bu konuda çok merkezli ve geniş vaka serili yayınlara ihtiyaç vardır.

\section{KAYNAKLAR}

Balague, C., Targarona, E.M., Cerdan, G., Novell, J., Montero, O., Bendahan, G., García, A., Pey, A., Vela, S., Diaz, M., Trías, M., 2004. Longterm outcome after laparoscopic splenectomy related to hematological diagnosis. Surg. Endosc. 18, 1283-1287.

Coad, J.E., Matutes, E., Catovsky, D., 1993. Splenectomy in lymphoproliferative disorders: A report of 70 cases and review of the literature. Leuk. Lymphoma. 10, 245-264.

Davies, J.M., Barnes, R., Milligan, D., 2002. Update of guidelines for the prevention and treatment of infection in patients with an absent or dysfunctional spleen. Clin. Med. J. Royal Coll. Phys. London. 2, 440-443.

Eichner, E.R., 1979. Splenic function: Normal, too much and too little. Am. J. Med. 66, 311-320.

Ejstrud, P., Kristensen, B., Hansen, J.B., Madsen, K.M., Schonheyder, H.C., Sorensen, H.T., 2000. Risk and patterns of bacteraemia after splenectomy a population-based study. Scand. J. Infect. 32, 521-525.

Girgin, S., Gedik, E., Baç, B., Taçyıldız, H., 2008. Benign hematolojik hastalıklarda splenektomi sonuçlarımız. Akademik Acil Tıp Dergisi. 7, 
$42-45$.

Katkhouda, N., Hurwitz, M.B., Rivera, R.T, Chandra, M., Waldrep, D.J., Gugenheim, J., Mouiel, J., 1998. Laparoscopic splenectomy: Outcome and efficacy in 103 consecutive patients. Ann. Surg. 228, 568-578.

Lutwick, L.I., 2005. Infections in asplenic patients. In: Mandell GL, Bennett JE, Dolin R, eds. Mandell, Douglas, and Bennett's Principles andPractice of Infectious Diseases. 6th ed. Philadelphia: Churchill Livingstone, 3524-3532.

Musser, G., Lazar, G., Hocking, W., Busuttil, R.W., 1984. Splenctomy for hemotologic disease. The UCLA experience with 306 patients. Ann. Surg. 200, 40-45.

Özkören, Ş., Pullukçu, H., Taşbakan, M., 2007. Splenektomili hastaların pnömokok aşısı ile bağışıklanma oranları ve diğer aşılar konusundaki bilgi düzeyleri; İnfeksiyon Dergisi (Turkish Journal of Infection) 21, 71-74.

Porembka, M.R., Doyle, M.B.M., Chapman, W.C., 2009. Disorders of the spleen. In: Greer J,Foerster J, Rodgers GM and Paraskevas F(eds):Wintrobe's Clinical Hematology, Piladelphia, Lippincott Williams\&Wilkins, pp. 1637-1655.

Schlachta, C.M., Mamazza, J., Poulin, E.C., 1999. Laparoscopic splenectomy for hematologic malignancies. Surg. Endosc. 13, 865-868.

Schwartz, P.E., Sterioff, S., Mucha, P., Melton, L.J. 3rd, Offord K.P., 1982. Post-splenectomy sepsis and mortality in adults. JAMA 248, 22792283.

Wang, T., Xu, M., Ji, L., 2005. Splenectomy for adult chronic idiopathic thrombocytopenic purpura: Experience from a single center in China. Eur. J. Hematol. 75, 424-429. 